documented, there is a good bibliography and the book will give great pleasure to all who are interested in the origins of today's highly industrialized society.

C. S. WHEWELL

\section{TOWN BLIGHT}

\section{Urban Decay}

An Analysis and a Policy. By Franklin Medhurst and J. Parry Lewis, with a chapter by Elizabeth Gittus. Pp. xvi + 174. (Macmillan: London, October 1969.) 65s.

THe problem of urban decay is undoubtedly one of the most urgent facing planners today. It is estimated that in 1961 between 2.5 and 3.5 million houses in England and Wales were in need of some kind of renewal, and that by 1981 another million houses will have been added to these. In spite of the apparent success of some local rencwal projects, planners are still basically undecided about the best way of handling the existing problem, and seem to have little idea about what ought to be done to make sure that urban decay is less of a problem in the future. The main reason for this seems to be that not enough is known about the conditions of decay, nor about the complex processes involved. Hence it is unfortunate that the authors of this slim volume cannot be considered to have made more than a superficial contribution to solving tho problem.

The empirical analyses reported in the book are unimpressive and somewhat disappointing. They add little to our knowledge of the conditions of decay and, regrettably, do not yield any new insights into the complex processes at work. This may bo because the studies seem to have been ill-conceived, in part because of the rather naive level of quantitative analysis that was used. This is particularly true of the attempts made to index the level of physical and environmental decay, and although the analysis of change in part of Manchester's twilight area is interesting, the details which are provided could have been put to better use. Instead, these details are used to suggest hypotheses which seem to form the basis of on-going research into the broader aspects of urban change presented at length in chapter five. It is a great pity that the discussion is in terms of what might be done rather than what has been done.

The book is, nevertheless, not without its good parts, and for me these include the short but excellent review of the sociological aspects of urban decay contributed by Elizabeth Gittus and the attempts made by the authors in the last chapter to formulate a policy towards decay. Here it is sensibly argued that greater effort should be made to repair decaying property rather than to demolish it, and a number of suggestions are made whereby the costs of repair could be reduced and the benefits to property owners increased. The authors stress, moreover, that any policy towards decay must be contained in a larger urban policy set within the broader framework of policies for regional development. Barry J. Garner

\section{Radiotelescopes}

\section{SOPHISTICATED AERIALS}

By W. N. Christiansen and J. A. Högbom. (Cambridge Monographs on Physics.) Pp. $\mathrm{x}+231$. (Cambridge University Press: London, September 1969.) $90 s ; \$ 14.50$.

Twenty-FIVE years ago a radio telescope was just an aerial, but today there are many sophisticated and elegant systems which bear little resemblance to Grote Reber's original telescope and which can extract and use the information in the incoming waves more efficiently than the classical parabolic reflector. 'The authors of this book, Christiansen and Högbom, have for many ycars been associated with the design of unusual radio telescope systems. Christiansen's grating telescope was used in very early studies of the radio sun and, when it was later multiplied with an orthogonal grating, the language of the art was enriched by the colourful "chris-cross". One would expect a book of quality from these authors and, indeed, one is not disappointed. It is aimed at the graduate or near-graduate level and will satisfy a demand for a reliable and almost complete reference work on the subject.

It is almost complete. One would not fault it because it could not include all the tricks of the trade. Nevertheless, one could not recommend it as the only reference work on radio telescopes to a class of budding radio astronomers. It would have to be garnished with a subsidiary work on aerials and practical tips. In the index and in the text, one looks in vain for Yagis, helices and all sorts of little facts and details that build up to the sophisticated systems that appear in the two hundred and twenty well printed pages. They are not to be found. How does one obtain circular polarization? How does one methodically tapor an cxtended aerial without tears and sweat, and what steps should be taken to maintain coaxial feeders constant on extended phased systems ? Chapter 6 tells one the facts about feeder attenuation that may be gleaned directly from the manufacturers' literature; it tells one that the beam may be steered by varying the phase, but it omits the associated problems of phase stability, though these problems were first tackled and solved by radio astronomers. Finally, a minor point of presentation: it would have been much easier to navigate from the "contents" sheet to the relevant pages if the page numbers had appeared in the contents.

These minor criticisms only represent the greed of the reviewer who would have liked to have had a little more for his money, but who would novertheless strongly recommend this little book to all radio astronomers, whether budding or fully fledged. It should also form part of the library not only of every department of astronomy, physics and electronics, but also all other sciences where these principles may yet find application.

R. C. JENNISON

\section{MODERN METEOROLOGY}

\section{Essentials of Meteorology}

By D. H. McIntosh and A. S. Thom. (The Wykeham Science Series for Schools and Universities.) Pp. $\mathrm{xv}+238$. (Wykeham: London and Winchester, 1969.) 20s.

THE teaching of meteorology in schools is usually undertaken by the geography master, with the result that students retain an impression of a collection of maps and statisties with little physical content. Some meteorologists believe that this leads to difficulties in attracting suitable workers to the field. Accordingly, they will welcome this admirable book by two staff members of the University of Edinburgh for its thoroughly scientific treatment of present meteorological knowledge at a level attainable in the upper forms of schools or early years of university.

The reader is introduced in considerable detail to almost all topics of interest to modern meteorology, a range too great to list here. Broadly, however, basic physical laws, such as Nowton's laws of motion and the gas laws, are cast into a form applicable to the elements. The reader will learn how atmospheric scientists picture weather phonomena from dust devils to cyclones and how they are observed, how the energy of these motions is replenished from the Sun and lost again to space, how their behaviour may be forecast and why such forecasts are expected to improve.

There are already available several texts which are intended as introductions to meteorology for enthusiastic sixth formers. The distinctive feature of this book is the unflinching use of mathematics, permitting brief and precise arguments and affording a more accurate and 